URL: http://dergipark.ulakbim.gov.tr/ijhbs/index

Volume: 1, Issue: 2, Year: 2015

\title{
The Characteristics of Effective EFL Teachers from the Perspective of Turkish EFL Learners
}

\author{
Burçin Baytur \\ Turkey \\ bbaytur@gmail.com \\ Salim Raz1 \\ Çanakkale Onsekiz Mart University, Turkey \\ salimrazi@gmail.com
}

\begin{abstract}
EFL teachers' characteristics may undergo alterations due to several factors including the teachers' personality and the methods that they pursue. The present paper is aimed to investigate the perceptions of young learners about the characteristics of effective English language teachers. In this respect, 100 students were delivered the Turkish version of an inventory that was developed by $\mathrm{Yu}-\mathrm{H} s i n$ (1999). It consisted of three different parts of regarding personal, professional and pedagogical qualities. The results indicated that an effective teacher was expected to be friendly, to have accurate pronunciation and to have effective classroom management skills. Moreover, the participants indicated that they expected EFL teachers to be enthusiastic about technological developments, while visual materials clearly helped them feel relaxed during the lectures. Since the overall results indicated the importance of both pedagogical and of personal qualities that help a professional to become an effective teacher, anyone who aims at becoming an effective EFL teacher should be fully aware of them.
\end{abstract}

Keywords: effective teacher, EFL, English language teacher, teacher characteristics

\section{Introduction}

It is commonly accepted that there are numerous hindrances in the world of education. A lot of reasons for these impediments may be identified as they have a clear effect on the learning and on the teaching process. For example, students might find the lesson too difficult to be successful, the materials for the lesson might be poor in quality, or students may not be aware of the reasons to study English.

Unavoidably, the process of teaching a language consists of several components and 'teachers' appear as the most essential component of this process. In order to achieve their teaching aims, teachers should address several issues in the classroom and find viable solutions to them. This could be regarded as an essential characteristic of an effective teacher. However, there should be some more characteristics that make a teacher effective. In addition, being aware of the expectations of Turkish EFL learners related to the characteristics of an effective EFL teacher may contribute to the design of more effective EFL teaching environments.

\subsection{Characteristic of an Effective Language Teacher (EFL)}

Teachers play a crucial role in the teaching process. That is why they have an enormous impact on learners. However, when teachers do not take into account the learners' needs, interests or their 
deficiencies, both the teaching and the learning processes become painful and the school becomes an unbearable place for students.

The characteristics of an effective teacher might be different for each learner. Although there are several different factors, some are common. In one of the related studies, for example, Cheung (2006, pp. 435-436) explains that effective teachers tend to:

- remain in their posts for longer periods of time;

- spend more time on teaching and curricular planning;

- be enthusiastic to teach;

- be sensitive towards their students' needs;

- be tolerant towards their students' mistakes and errors;

- work with problem students for longer periods of time;

- participate in and contribute to the learning experiences of their students.

Cheung's characteristics reflect the perception of a modern EFL teacher in accordance with the post-method era. Yet, it is possible to enlarge this list by adding some more elements. For instance, Brosh's (1996) study might be beneficial in adding new components. According to Brosh, an effective teacher should:

- be able to organize, explain and clarify instructions;

- be knowledgeable in target language;

- raise and sustain interest and motivation among students;

- be fair to students by showing neither favoritism nor prejudice;

- be constantly available for students.

Apart from these two lists of common expectations, Pettis (1997) provides three major qualities for an expert teacher. Therefore, an effective teacher's paramount feature is to highlight the importance of being moral and well-informed apart from being competent. The second criterion indicates that the teacher should constantly attempt to detect new ways of professionally enhancing himself, in accordance with his / her previous experience. Lastly, the third criterion is that the teacher must be personally committed to the progress of his / her profession. As highlighted by Pettis, the profession of being a teacher requires the integration of life-long learning by teachers.

In accordance with humanistic approaches, Richards (2002) provides some additional characteristics for effective teachers. In his view, creating a friendly classroom atmosphere, planning different kinds of learning activities and using educational materials represent an effective teacher's professional duties. Moreover, they should also be aware of planning their lesson and classroom in order to decrease their students' anxiety this way encouraging them to speak in English. As a conclusion to the aforementioned information with reference to existing block of literature, there are several features of an effective language teacher that converge from different perspectives.

\subsection{Significance of the Study}

As teaching quality is a crucial factor in promoting effective learning, it would be highly beneficial if teachers knew precisely what their students consider as true characteristics of an effective teacher. Being familiar with these perceptions will assist teachers in understanding their students' expectations and it will enable them to enhance their own skills accordingly. The existing block of literature provides information about the perception of Turkish preparatory school students at higher education setting (e.g. Arıkan, Taşer, \& Saraç-Süzer, 2008). However, there is a clear need for the investigation of younger learners at secondary and at high school level. 


\subsection{Research Questions}

The present study addresses the following research questions:

1. Which characteristics do the 6th graders regard as being most important in the identification of an effective teacher?

2. Which characteristics do the 12th graders regard as being most important in the identification of an effective teacher?

3. Which characteristics are commonly regarded as the most important ones in the identification of an effective teacher?

4. Does the perception of an effective teacher differ with reference to classes?

5. Is there a gender difference in the perception of an effective teacher?

\section{Method}

In order to find out how foreign language learners perceive the qualities of an effective foreign language teacher, Yu-Hsin's (1999) inventory was applied. It constituted of a total number of 30 items in three different sections. There were 10 items in each section. The first section of the inventory dealt with the personal qualities of teachers, the second one with the professional qualities and the third one with the pedagogical qualities. All the items in each section were rated on a four point Likert scale ( 1 = not important, $2=$ important, $3=$ very important, $4=$ it is a must $)$. Since the participants' proficiency was inadequate for answering the inventory items in English, it was translated into Turkish, the native language of the researchers. Afterwards, back translation was completed, in order to guarantee that there was no change in the meaning of the translated inventory. The original inventory was reliable since Cronbach's alpha coefficients $\alpha=.87$ over 30 items. Then, by the aid of this inventory, the collected data proved reliable.

\subsection{Setting}

The inventory was delivered to the 6th grade students at Sinasi ve Figen Bayraktar Secondary School and Turgut Reis Secondary School in Çanakkale, Turkey in November 2014. It was also delivered to the 12th grade students at İskilip Anatolian High School in Çorum and Biga Atatürk Anatolian High School in Çanakkale, in November 2014. All the participants were Turkish EFL learners.

\subsection{Participants}

A total number of 100 students agreed to answer the statements in the inventory. There were 47 male and 53 female participants in total and their ages ranged from 12 to 18 . Table 1 presents the details regarding the participants of the study.

Table 1: Gender and School Distribution of the Participants $(N=100)$

\begin{tabular}{|c|c|c|c|c|}
\hline \multirow[b]{2}{*}{ School } & \multicolumn{2}{|c|}{ Gender } & \multirow[b]{2}{*}{ Class } & \multirow[b]{2}{*}{ Tota } \\
\hline & Male & Female & & \\
\hline İskilip Anatolian High School & 9 & 16 & 12 & 25 \\
\hline Biga Atatürk A. High School & 14 & 11 & 12 & 25 \\
\hline Şinasi ve Figen B. Sec. School & 11 & 14 & 6 & 25 \\
\hline Turgut Reis Secondary School & 13 & 12 & 6 & 25 \\
\hline Total & 47 & 53 & - & 100 \\
\hline
\end{tabular}

\subsection{Data Collection}

The participants were all informed about the aims of the present study and those students who agreed to participate were delivered a hard copy of the questionnaire. Before answering the questions, they were also informed about the number of questions in the inventory and the approximate duration of the answer. The inventory was delivered during a regular school day with the aid of their English teachers (EFL). 


\subsection{Limitation of Study}

Since the study involved a limited number of participants, the results may not be generalized. In addition, the study collected all the data only by means of a written inventory.

\subsection{Data Analysis}

The data collected through the questionnaire was entered into computer through SPSS (Statistical Package for Social Sciences, version 22). The data was analysed by descriptive statistics, correlation and independent samples t-test.

\section{Findings}

The following are the results of the student questionnaire describing the qualities of effective teachers in accordance with the research questions of the study.

Research Question 1: Which characteristics do the 6th graders regard to be the most important ones in the identification of an effective teacher?

The main scores related to the characteristics of an effective teacher retrieved from the answers of the 6th graders are presented in Table 2.

Table 2: Scores of the $6^{\text {th }}$ Grades in Descending Order $(n=50)$

\begin{tabular}{lrr}
\hline Item & Mean & SD \\
\hline Uses technology & 3.70 & .65 \\
Teaches both formal and informal English & 3.48 & .79 \\
Has correct pronunciation & 3.40 & .95 \\
Manages the class effectively & 3.40 & .76 \\
Friendly & 3.36 & .90 \\
Caring & 3.34 & .87 \\
Makes the students feel relaxed & 3.34 & .75 \\
Enthusiastic & 3.32 & .89 \\
Uses pair and group work & 3.32 & .77 \\
Fair & 3.30 & .84 \\
Experienced & 3.30 & .84 \\
Knows native and target culture & 3.24 & .89 \\
Creative & 3.22 & .82 \\
Young & 3.14 & .99 \\
Gender & 3.12 & 1.14 \\
Makes students correct each others' work & 3.06 & .96 \\
Is the central authority in the class & 3.06 & .84 \\
Give tests, quizzes & 3.04 & .86 \\
Uses real life situations & 3.02 & 1.02 \\
Teachers grammar & 2.90 & 1.06 \\
Makes learners discover language & 2.84 & .89 \\
Non-native but fluent in English & 2.84 & .96 \\
Gives homework & 2.82 & .96 \\
Humorous & 2.68 & 1.08 \\
Takes attendance & 2.66 & 1.10 \\
Uses plays, games & 2.28 & .99 \\
Talks rather than listens & 2.24 & .94 \\
Native speaker of English & 1.56 & .91 \\
Has lived in a foreign country & 1.46 & .76 \\
Strict & 1.40 & .73 \\
\hline
\end{tabular}


Table 2 presents the participants' scores in a descending order. According to the table, the highest values were attached to the characteristics of 'uses technology' $(\mathrm{M}=3.70)$ and 'teaches both formal and informal English' $(M=3.48)$; while the lowest values were attached to the characteristics of 'has lived in foreign country' $(M=1.46)$, and 'strict' $(M=1.40)$.

Research Question 2: Which characteristics do the 12th graders regard to be the most important ones in the identification of an effective teacher?

The scores related to the characteristics of an effective teacher retrieved from the answers of the 12th grades are presented in Table 3.

Table 3: Scores of the $12^{\text {th }}$ Grades in Descending Order $(n=50)$

\begin{tabular}{lrr}
\hline Item & Mean & SD \\
\hline Makes students feel relaxed & 3.80 & .45 \\
Manages class effectively & 3.80 & .45 \\
Uses pair and group work & 3.78 & .42 \\
Fair & 3.56 & .79 \\
Has correct pronunciation & 3.54 & .65 \\
Friendly & 3.52 & .81 \\
Enthusiastic & 3.48 & .76 \\
Uses technology & 3.32 & .87 \\
Teaches both formal and informal English & 3.30 & .74 \\
A nonnative but fluent in English & 3.30 & .93 \\
Uses real life situations & 3.14 & .99 \\
Caring & 3.14 & .88 \\
Creative & 3.14 & .83 \\
Makes learners discover language & 3.10 & .81 \\
Teachers grammar & 3.08 & 1.00 \\
Knows native and target culture & 3.00 & .95 \\
Gender & 2.82 & .94 \\
Humorous & 2.82 & .94 \\
Uses plays, games & 2.76 & 1.12 \\
Young & 2.74 & 1.12 \\
Talks rather than listens & 2.48 & 1.15 \\
Makes students correct each others works & 2.42 & 1.07 \\
Is central authority in the class & 2.36 & 1.17 \\
Give tests, quizzes & 2.16 & 1.02 \\
Experienced & 2.12 & .98 \\
Has lived in a foreign country & 1.96 & 1.01 \\
Takes attendance & 1.94 & 1.17 \\
A native speaker of English & 1.88 & 1.02 \\
Gives homework & 1.74 & .94 \\
Strict & 1.56 & .81 \\
\hline
\end{tabular}

Table 3 presents the participants' scores in a descending order. According to the table, the highest values were attached to the characteristics of 'makes students feel relaxed' $(M=3.80)$ and 'manages class effectively' $(\mathrm{M}=3.80)$; while the lowest values were attached to the characteristics of 'gives homework' $(\mathrm{M}=1.74)$ and 'strict' $(\mathrm{M}=1.56)$. 
Research question 3: Which characteristics are commonly regarded to be the most important ones in the identification of an effective teacher?

The scores related to the characteristics of an effective teacher retrieved from the answers of all participants are presented in Table 4.

Table 4: Scores of All Participants in Descending Order $(\mathbf{N}=100)$

\begin{tabular}{lrr}
\hline Items & Mean & SD \\
\hline Correct pronunciation & 3.74 & .54 \\
Friendly & 3.55 & .72 \\
Effective class management & 3.46 & .93 \\
Enthusiastic & 3.45 & .77 \\
Uses technology & 3.43 & .78 \\
Makes students feel relaxed & 3.42 & .79 \\
Uses pair and group work & 3.39 & .80 \\
Teach formal and informal English & 3.33 & .91 \\
Makes students discover language & 3.32 & .80 \\
Teaches grammar effectively & 3.27 & .83 \\
Fair & 3.18 & .82 \\
Knows native and target culture & 3.12 & .92 \\
Uses real life situations & 3.08 & 1.00 \\
A nonnative but fluent in English & 3.08 & .94 \\
Experienced & 2.99 & 1.03 \\
Caring & 2.97 & .86 \\
Young & 2.94 & 1.07 \\
Humorous & 2.82 & .95 \\
Gender & 2.75 & 1.00 \\
Makes students correct each others' work & 2.74 & 1.06 \\
Is the central authority in the class & 2.71 & 1.08 \\
Takes attendance & 2.67 & 1.29 \\
Gives homework & 2.61 & 1.23 \\
Give tests, quizzes & 2.60 & 1.04 \\
Uses plays, games & 2.52 & 1.08 \\
Creative & 2.39 & 1.07 \\
Talks rather than listens & 2.36 & 1.05 \\
Native speaker of English & 1.72 & .98 \\
Has lived in a foreign country & 1.71 & .92 \\
Strict & 1.48 & .77 \\
\hline & & \\
& &
\end{tabular}

Table 4 presents the participants' mean scores in a descending order. According to the table, the highest values were attached to the characteristics of 'having good pronunciation' $(M=3.74)$ and 'friendly' $(\mathrm{M}=3.55)$; while the lowest values were attached to the characteristics of 'has lived in foreign country' $(\mathrm{M}=1.71)$ and 'strict' $(\mathrm{M}=1.48)$.

Research Question 4: Does the perception of an effective teacher differ with reference to classes?

In order to answer the 4th research question, we compared the answers of the participants from two different grades, by means of an independent sample t-test. Table 5 presents the results of the independent sample t-test. 
Table 5: Comparison of the $6^{\text {th }}$ and $12^{\text {th }}$ Grades Perceptions

\begin{tabular}{lrrrrrc}
\hline Grade & $\mathrm{N}$ & Mean & SD & df & t & p \\
\hline $6^{\text {th }}$ grade & 50 & 2.92 & .41 & \multirow{2}{*}{.98} & .87 & .39 \\
$12^{\text {th }}$ grade & 50 & 2.85 & .39 & & & \\
\hline
\end{tabular}

Although descriptive statistics highlight differences related to individual items in the answers of the 6 th and 12th grades, as indicated in Table 5, the results of the independent samples t-test over the mean values did not indicate statistically significant differences between the 6th graders' $(\mathrm{M}$ $=2.92, \mathrm{SD}=.41)$ and the 12 th graders' $(\mathrm{M}=2.85, \mathrm{SD}=.39)$ perceptions about the characteristics of an effective teacher, $\mathrm{t}(98)=.87, \mathrm{p}>.05$.

Research Question 5: Is there a gender difference in the perception of an effective teacher? In order to answer the 5th research question, we compared the participants' scores in two different grades by means of an independent samples t-test. Table 5 presents the results of the present independent samples t-test.

In order to answer the 5th research question, an independent samples t-test was conducted to the mean values of female and male participants. Table 6 presents the results of the independent samples t-test.

Table 6: Gender Differences Regarding the Perception of Effective Teachers

\begin{tabular}{lrrrrrc}
\hline Gender & $\mathrm{N}$ & Mean & SD & df & t & p \\
\hline Female & 53 & 2.93 & .42 & \multirow{2}{*}{.98} & 1.01 & .32 \\
Male & 47 & 2.85 & .38 & & & \\
\hline
\end{tabular}

As detailed in Table 6, the results of the independent samples t-test did not indicate statistically significant differences between the female participants' $(\mathrm{M}=2.93, \mathrm{SD}=.42)$ and the male participants' $(\mathrm{M}=2.85, \mathrm{SD}=.38)$ perceptions about the characteristics of an effective teacher, $\mathrm{t}(98)=1.01, \mathrm{p}>.05$.

\section{Discussion, Conclusion and Implications}

As our findings indicated, firstly, the participants had different perceptions about an effective teacher's characteristics. For example, with regard to the pedagogical part of the inventory, students from two different grades would rather value their teacher's good pronunciation skills in English. Regarding the lack of oral EFL practice skills in Turkish state schools, this finding seems to be of utter importance. In accordance with the participants' expectations from an effective teacher, it can be inferred that students also expect more exposure to the target language in a correct way. Therefore, EFL teachers should be careful about their pronunciation with a specific emphasis on their fossilized pronunciation errors. Avoiding such errors will enable EFL learners to have vast exposure to correct English language, which will result in more productive language skills on a long term basis.

The 12th grade students gave more importance to personal qualities of a teacher than the 6th graders. The teacher's personal qualities proved to have a vital importance not only for an effective language teaching but also for the moral development of the student. Since teenagers aim to find their personality or identity during their high school years, serving as a proper role model to these students should become the teacher's paramount professional aim. In his study, Thompson (2008) supports the importance of the teacher's personal qualities by stating that an effective teacher blends well-built teaching skills with good character traits. Such teachers have a key role in becoming and being friendly pedagogues. Consequently, friendliness, as opposed to strictness, becomes a basic characteristic that any effective teacher should possess. 
In the same line of thought, Brosh (1996), Shishavan and Sadeghi (2009) and Thompson (2008) highlight the importance of an effective teacher's personal traits. For example, Shishavan and Sadeghi argue that "being of good character and behaving with the students in a friendly manner is very important for a teacher to be effective" (p. 135). This enables learners to study in a nonthreatening environment that would have a positive impact on language learning. In addition to these studies, Clark and Walsh (2002) and Cheung (2006) also highlight to the importance of creating a positive relationship with students as an essential quality of an effective teacher. In this respect, teachers should be aware of their behaviour with students since it plays a significant role in setting a healthy environment for teaching and learning.

The participants' replies pinpointed the importance of effective classroom management skills. Students from two different grades regarded teachers as effective, if they were able to manage the classroom effectively. This implies that they expected their teachers to plan their lessons carefully. Then, they should follow the procedure that they were familiar with, relying on their lesson plans. Motivation is believed to be an important component both in language learning and in the teaching process. At the first phase, EFL teachers are responsible for motivating themselves to be enthusiastic during their own lessons. This will encourage them to motivate their learners better in order to learn English.

By considering the recent developments in technology, it would not be possible to design an effective language learning environment without benefiting from technological devices such as computers, projectors, smart boards, etc. Recently, almost every EFL learner may be regarded as a digital native therefore they expect their teachers to incorporate such technological devices into their classes. Implementing such appropriate devices is helpful both in intensive and in extensive practices. They may also be regarded as useful for motivating students by drawing their attention. In the previous language teaching methods, teachers had an active role. However, such a perception does not seem to be relevant any longer. For example, the results of the present study highlight the fact that learners expect their teachers to design activities that require collaboration, such as group work and pair work. This is a qualification related to the professional quality of the teacher.

Teachers should also consider the variations of the English language. The results indicate that students have the ambition to familiarize themselves not only with formal English but also with the informal language. It means that they prefer the communicative function of the English language. If their only exposure to the target language is restricted to the formal instances, then they might experience difficulty in communicating in informal environments. Therefore, in order to meet their students' expectations, teachers may benefit from authentic materials in the classroom.

Teachers should also pay attention to the process of teaching grammar. Previously, language teaching methods regarded accuracy as being clearly superior to fluency. However, this is not the case in contemporary EFL classrooms. Although producing grammatically correct sentences is an important skill for any language learner, becoming a fluent speaker of the target language proves more important. Therefore, teachers need to provide exposure to the target language syntax in an inductive way. This will permit learners to discover the accuracy rules on their own.

In addition to the characteristics that are highly appreciated by their learners, EFL teachers should also familiarize themselves with the characteristics that should be avoided. The results of the present study indicate that students do not wish their teachers to be strict in the classroom. This is an expectation parallel to the humanistic approaches. In case of establishing closer contact with the students by avoiding strictness and harshness, teachers may develop better relations with their students and this will result in their students' higher performance. 
By considering all the aforementioned findings and discussions, it is possible to conclude the following characteristics of an effective EFL teacher. Thus, an effective EFL teacher should master good / excellent English pronunciation, he should provide his students with a friendly classroom atmosphere, have good classroom management skills, be enthusiastic and patient and take integrate technology and visual materials into his pedagogical act.

\section{References}

Arıkan, A., Taşer, D., \& Saraç-Süzer, H. S. (2008). "The effective English language teacher from the perspectives of Turkish preparatory school students". Education and Science, 33, 4251.

Brosh, H. (1996). "Perceived characteristics of an effective language teacher". Foreign Language Annals, 29(2), 25-38.

Cheung, H. Y. (2006). "The measurement of teacher efficacy: Hong Kong primary in-service teachers". Journal of Education for Teaching, 32, 435-451.

Clark, J. C., \& Walsh, J. (2002). Elements of a model of effective teachers. AARE 2002 Conference papers. Retrieved April 24, 2015 from http://www.aare.edu.au/02pap/wal02220.htm

Pettis, J. (1997). "Developing our professional competence; Some reflections". TESL Canada Journal, 16(2), 67-71.

Richards, J. (2002). "30 years of TEFL/TESL: A personal reflection”. RELC Journal, 33(2), 135 .

Shishavan, H. B., \& Sadeghi, K. (2009). "Characteristics of an effective English language teacher as perceived by Iranian teachers and learners of English". English Language Teaching, 2(4), 131-143.

Thompson, S. (2008). "Defining a good teacher simply!". Modern English Teacher, 17(1), 5-14.

Yu-Hsin, T. (1999). "Examining student perceptions of the ideal language instructor". Hwa Kang Journal of TEFL, 5, 1-26. 